\title{
Design of Optical 2-Channel Demultiplexer Using Selective Optofluidic Infiltration within Photonic Crystal Structure
}

\author{
Mahsa BAZARGANI, Behnaz GHAREKHANLOU, Mehdi BANIHASHEMI \\ Dept. of Electrical Engineering, Central Tehran Branch, Islamic Azad University, Tehran, Iran \\ beh.gharekhanlou@iauctb.ac.ir
}

Submitted March 29, 2020 / Accepted June 30, 2020

\begin{abstract}
In the current study, a compact demultiplexer for telecommunication applications using $2 D$ photonic crystals with a hexagonal lattice structure is presented. This demultiplexer consists of two L6 resonant cavities as filters and 6 holes around each cavity for optofluidic infiltration. Through the use of this structure, the communication wavelengths of $1550 \mathrm{~nm}$ and $1567 \mathrm{~nm}$ with the transmission coefficient of $84 \%$ and $96 \%$ respectively can be selected without any change on the size of the radius of holes. The average value of crosstalk between two channels is $-18.35 \mathrm{~dB}$. The plane wave expansion method is employed in order to extract the photonic band gap and the finite difference time domain method is implemented to study the behavior of propagation of light in the structure.
\end{abstract}

\section{Keywords}

Photonic crystal, band gap, optofluidic, demultiplexer, resonant cavity

\section{Introduction}

Nowadays, designing the smallest device size is a very important factor in telecommunication applications in which the main challenge is how to lock and control the light in the very small space. According to recent studies, one of the best methods for light controlling is using the photonic crystals (PCs) [1], [2]. These structures have periodic arrangement, in which the refractive index of materials changes periodically and as a result, a forbidden region of wavelengths can be created against propagation as photonic band gap (PBG) [3], [4]. This region can be controlled by adjusting the lattice constant, dielectric constant of the materials and the radius of components in the structure. In fact, by using these parameters the interval of reflection wavelengths and transmission wavelengths can be adjusted [5], [6]. Considering various structural defects, certain wavelengths can be directed in PBG. Therefore, the location and size of defects in the structure are very significant factors to control the transmitted wavelengths and the realization of all optical devices can be achieved by creating some defects such as point or line defects. So far, by considering the defects and breaking the region of photonic band gap, various devices such as buffers, delay lines [7], polarization splitters [8], power splitters [9], optical switches [10], modulators [11], optical logic gates [12], optical sensors [13], optical filters and demultiplexers [14-20] have been proposed. One of the most important applications of crystal photonic in the telecommunication systems is the realization of optical demultiplexers because by using the wavelength division multiplexing (WDM) technology, multiple channels through one optical fiber can be transferred and then at the end of the transmission line the channels can be separated from each other by applying optical demultiplexer. To design demultiplexers, various structures have been heretofore introduced and in all of them the selection and separation of wavelength are achieved by changing the distance between the components of structure or by modifying the radius of them. In this study, an easy method is presented to design demultiplexer without any change on the size of holes' radius by infiltrating the holes only.

In designing the photonic crystal devices, in the first step the photonic band gap (PBG) needs to be adjusted in a way that suits our intended use. To extract the region of photonic band gap and investigate the electromagnetic wave behavior in photonic crystal structure, some numerical solutions should be employed. The two popular methods for numerical solutions are the plane wave expansion (PWE) method [21] and the finite difference time domain (FDTD) method [22]. To extract the band structure diagrams and calculate the PBG region, PWE method is used. The PWE is an interesting numerical method in frequency domain that makes it possible to calculate eigen modes in an unlimited alternating structure. However, a point at issue of PWE is that it is confined to only the constant state calculation. Thus, the PWE method is not effective for obtaining the reflection and normalized output spectrum. Another method that has the flexibility to simulate the complex problems is FDTD method. The FDTD is the accurate and efficient method for solving the Maxwell's equations in time domain and it can be used to analyze 


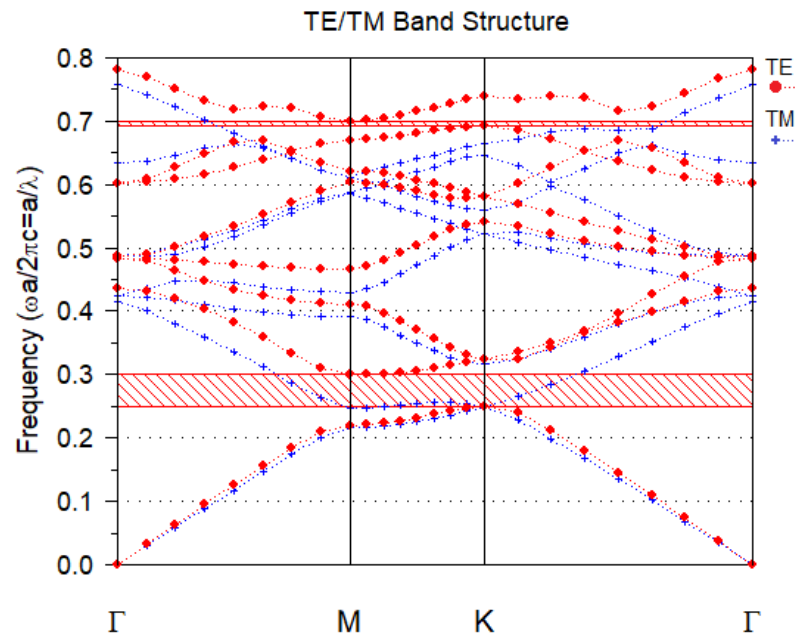

Fig. 1. The band structure diagram for the proposed structure.

electromagnetic waves propagated through photonic crystal structure. In this study, the Bandsolve simulation tool of RSoft software is utilized to calculate the band structure and extract the PBG based on PWE method and the fullwave simulation tool is employed to simulate and study the behavior of electromagnetic waves.

\section{Design Procedure}

In this regard, the hexagonal lattice structure of air holes with the radius of $r=115 \mathrm{~nm}$ in dielectric slab with the effective refractive index of 2.8 is used in which the value of lattice constant of PCs structure is $420 \mathrm{~nm}$ and the array of holes is considered as 30 in $X$ direction and 20 in $\mathrm{Z}$ direction. In Fig. 1, the band diagram of structure without any defects is plotted along the edges of irreducible Brillouin zone $(\Gamma, \mathrm{M}$ and $\mathrm{K}$ are the three corners of the irreducible Brillouin zone) and the frequency axis is normalized by the lattice constant. It can be seen that there are only two photonic band gaps in transverse electronic (TE) mode and the structure does not have PBG for transverse magnetic (TM) mode. In the TE mode of PCs, electric field components of light are perpendicular to air holes. Thus, we used the TE mode in the current simulation. According to Fig. 1, as shown by the dispersion curve of structure, there are two PBGs in $0.25 \leq a / \lambda \leq 0.3$ and $0.69 \leq a / \lambda \leq 0.7$ range. The first PBG in TE mode will be in $1400 \leq \lambda \leq 1640$ (nm) wavelength range by choosing $a=420 \mathrm{~nm}$. This range of wavelengths indicates that this basic structure is suitable for designing of optical telecommunication devices.

At this step, the main purpose is to achieve filters with the capability of selecting and filtering the desired wavelengths. Cavities in photonic crystals have the ability to select central wavelengths with narrow bandwidth and high efficiency, and they are also easy to integrate. Note that the cavities in this design must be adjusted in the range of optical telecommunication's wavelengths. Therefore, the resonance wavelength of cavities should be set near $1550 \mathrm{~nm}$ at which the intensity of output should be higher

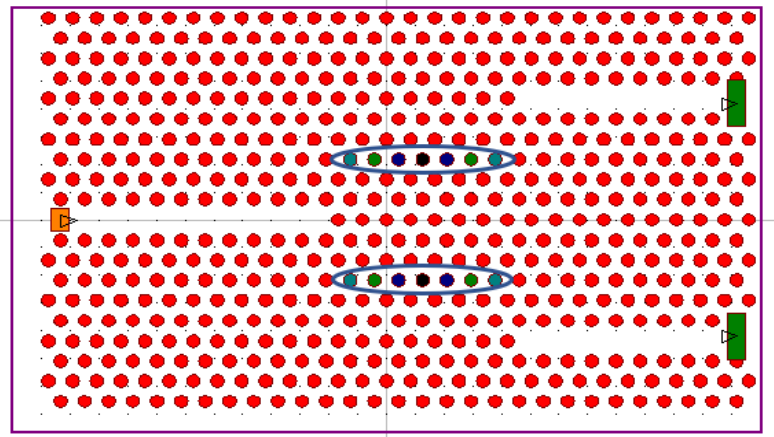

(a)

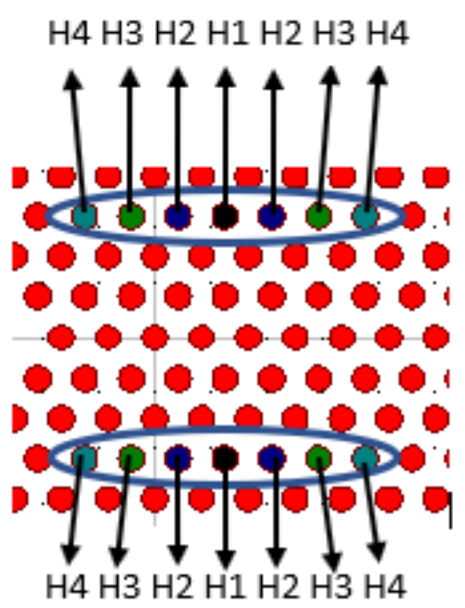

(b)

Fig. 2. (a) 7 holes are examined for each of the cavities in the structure, (b) names of the holes.

and the presence of undesirable wavelengths should be reduced. This design consists of an input waveguide and two output waveguides, and there is a resonant cavity between the input waveguide and each of the output waveguides for filtering.

In order to analyze the performance of cavities, 7 holes are considered for each of them, as shown in Fig. 2. In each step, by removing each of the marked holes, the output is examined.

To create the two L1 cavities, we removed the $\mathrm{H} 1$ holes from the structure. The output spectrum of both channels is shown in Fig. 3.

To create the two L3 cavities, we removed the H1 and $\mathrm{H} 2$ holes from the structure. The output spectrum of both channels is shown in Fig. 4.

To create the two L5 cavities, we removed the H1, H2 and $\mathrm{H} 3$ holes from the structure. The output spectrum of both channels is shown in Fig. 5.

To create the two L7 cavities, we removed the H1, $\mathrm{H} 2, \mathrm{H} 3$ and H5 holes from the structure. The output spectrum of both channels is shown in Fig. 6 .

To create the two L6 cavities, we removed the H1, $\mathrm{H} 2, \mathrm{H} 3$ and only the left $\mathrm{H} 4$ holes from the structure. The output spectrum of both channels is shown in Fig. 7. It can 
be found from Fig. 7 that by removing 6 holes (L6 cavity), the intensity at the outputs is higher and the undesirable wavelengths are less than those with L1, L3, L5 and L7 cavities. Due to the same conditions of both cavities, they have the same central wavelength, and according to Fig. 7, both output channels are perfectly aligned with each other.

At this step, we used optofluidic infiltration to separate the output of two channels from each other, by testing some holes around the cavities. We selected 6 holes for optofluidic infiltration around each of the cavities ( 3 upper holes and 3 lower holes).

The two suitable fluids for infiltration into the holes are water with the refractive index of 1.31 and benzene with the refractive index of 1.47 [23].

According to Fig. 8(a), in simulating the structure, the refractive index of six holes around the upper cavity was considered to be 1.47 and the refractive index of the six holes around the lower cavity was considered to be 1.31 . Since the refractive index of holes around the cavities has increased, resonance wavelength of the cavity is expected to be shifted. As the refractive index of the holes increases,

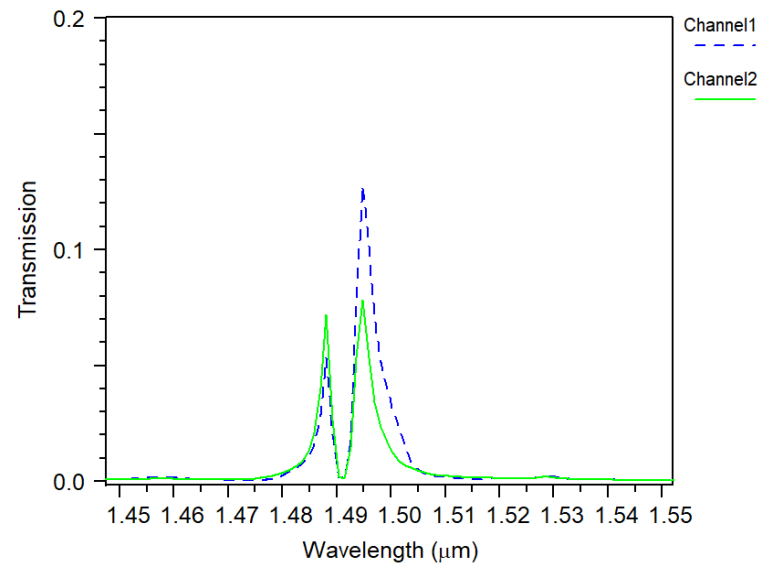

Fig. 3. The output spectrum resulting from the removal of $\mathrm{H} 1$ holes.

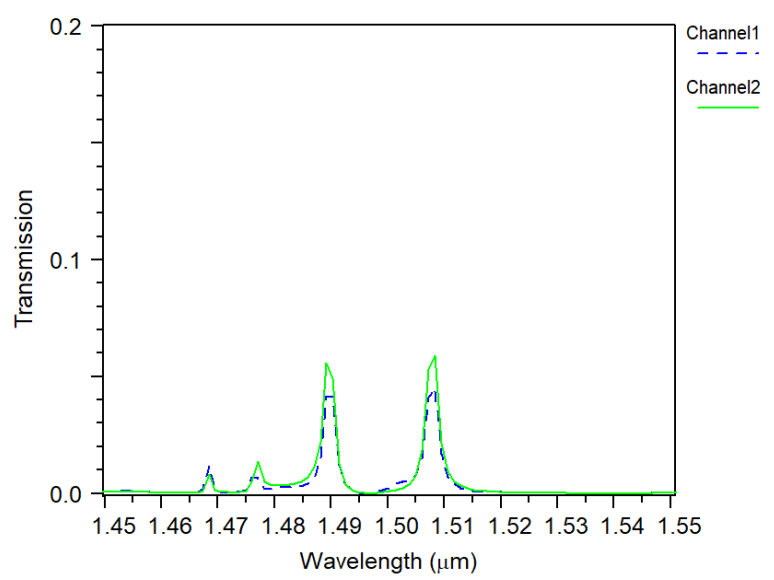

Fig. 4. The output spectrum resulting from the removal of $\mathrm{H} 1$ and $\mathrm{H} 2$ holes.

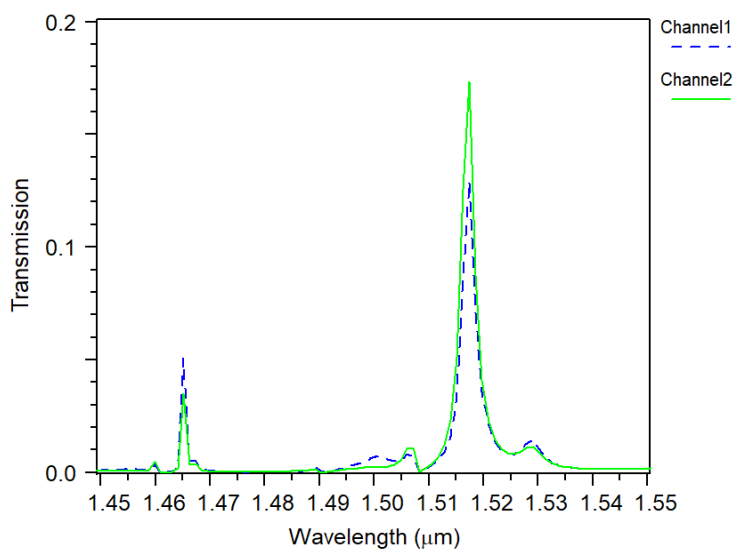

Fig. 5. The output spectrum resulting from the removal of $\mathrm{H} 1$, $\mathrm{H} 2$ and $\mathrm{H} 3$ holes.

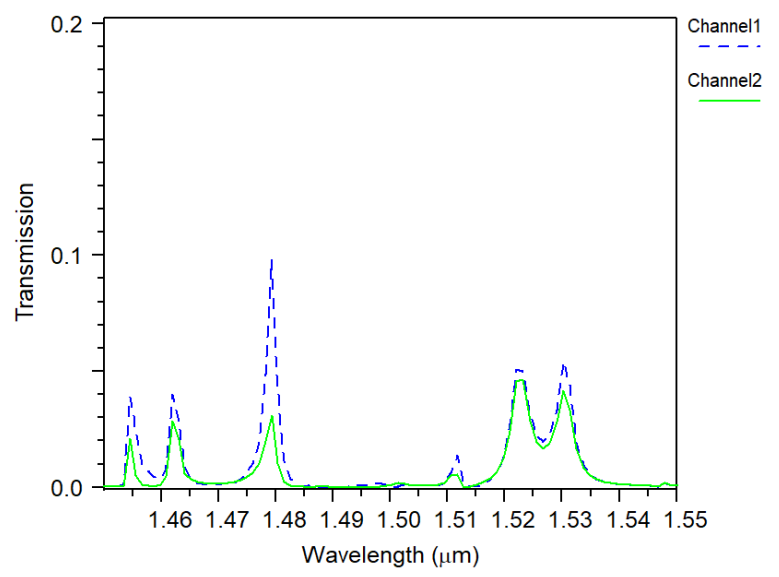

Fig. 6. The output spectrum resulting from the removal of $\mathrm{H} 1$, $\mathrm{H} 2, \mathrm{H} 3$ and $\mathrm{H} 4$ holes.

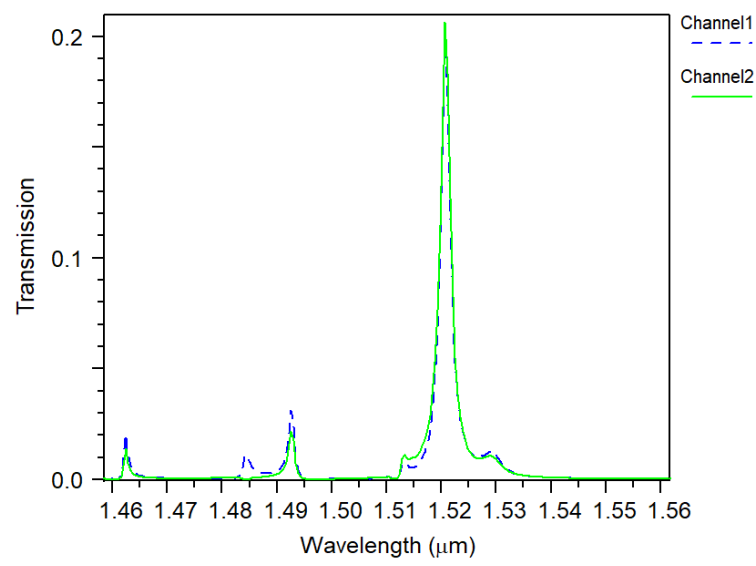

Fig. 7. The output spectrum resulting from the removal of $\mathrm{H} 1$, $\mathrm{H} 2, \mathrm{H} 3$ and the left $\mathrm{H} 4$ holes.

the selected wavelength shifts to greater wavelengths. In Fig. 9, performance of the designed demultiplexer in linear (a) and decibel (b) mode is shown.

As expected, the wavelength has shifted and two resonant modes have appeared in $1550 \mathrm{~nm}$ and $1567 \mathrm{~nm}$ with a transmission efficiency of $84 \%$ and $96 \%$, respectively. 


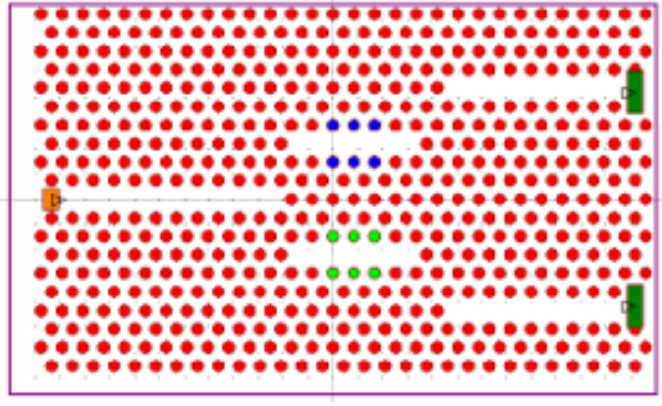

$\mathrm{CH} 1$

(a)

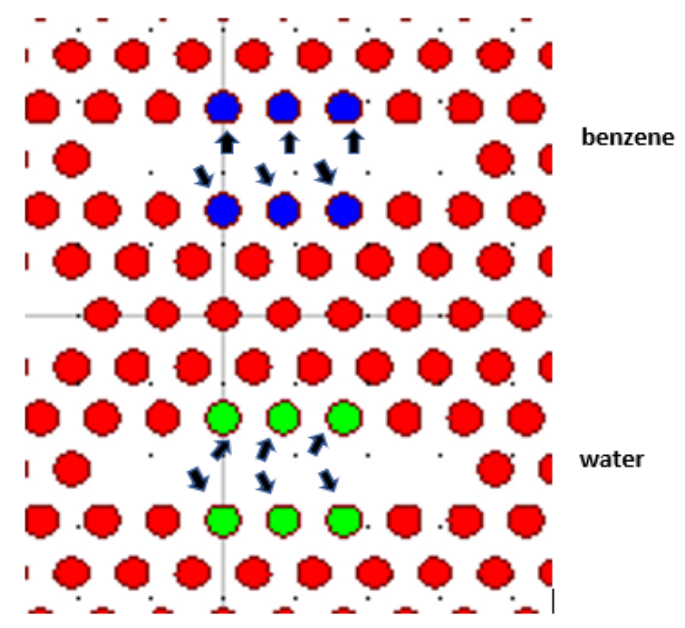

(b)

Fig. 8. (a) The proposed structure with two L6 cavities. (b) More details of the two cavities and marked 6 holes around them to be infiltrated with benzene and water.

\section{Simulation and Results}

In this work, we used the FDTD method to design and simulate the behavior of electromagnetic waves in the structure using the full-wave simulation tool. An accurate simulation of photonic crystal structures requires $3 \mathrm{D}$ calculations that are very time consuming and it requires large size of memory as well as very powerful computer systems. The simulation of photonic crystal structure is possible through the use of the effective index approximation by reducing the full $3 \mathrm{D}$ calculations to simpler, through approximate $2 \mathrm{D}$ calculations. Therefore, to make calculations easier using the effective refractive index method, we have assigned the value of $n_{\text {eff }}=2.8$ to the dielectric material in structure for 2D FDTD simulation. In order to use this method, precise meshing and time calculations are required. Due to the high performance of the perfectly matched layer boundary condition (PML), it is employed in the present simulations. In these simulations the width of PML around the structure has been considered as $500 \mathrm{~nm}$. Our structure consists of air holes in the dielectric layer in the x-z plane. The mesh size that is commonly used in simulations is between $a / 20$ and $a / 10$ (in which $a$ refers to lattice constant). The grid sizes in FDTD mesh (space steps $x$ and $z$ ) are chosen as $\Delta x=\Delta z=a / 16$ which are equal to $26.25 \mathrm{~nm}$.

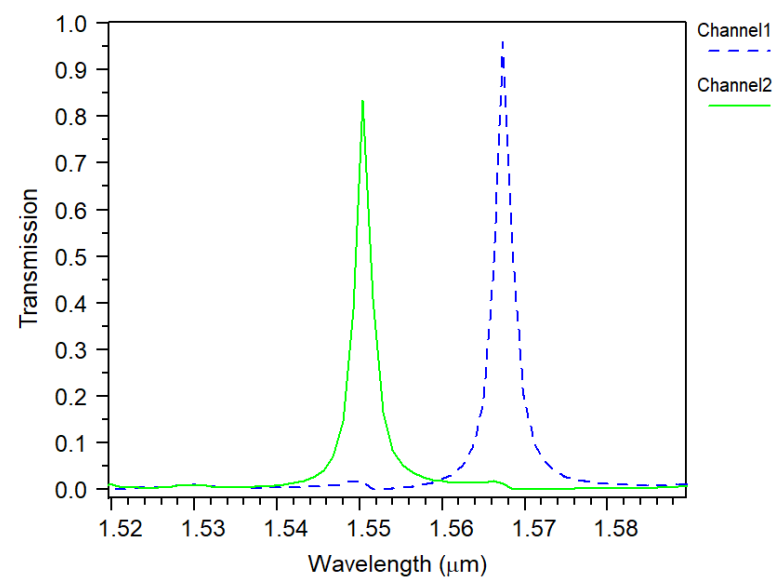

(a)

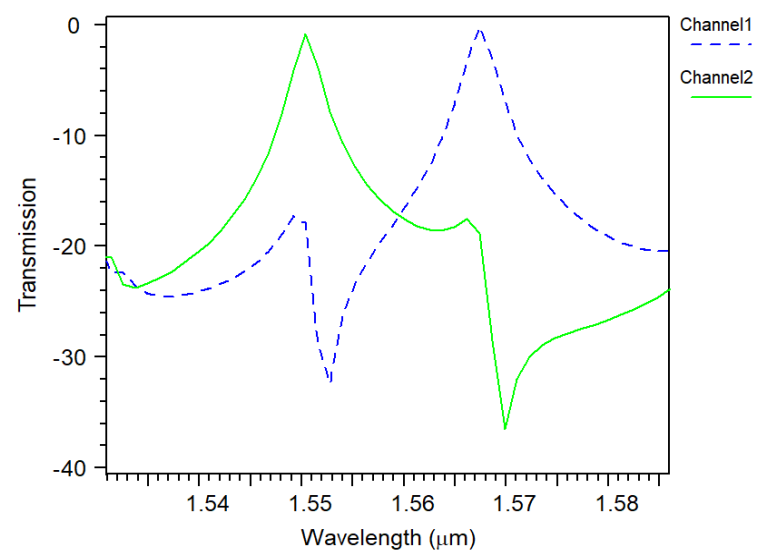

(b)

Fig. 9. (a) Spectral output for 2-channel, linear scale. (b) Spectral output for 2-channel, decibel (log) scale.

For 2D structures, after determining the space steps, the time step is obtained from (1)

$$
\Delta t \leq\left(c \sqrt{\frac{1}{\Delta x^{2}}+\frac{1}{\Delta z^{2}}}\right)^{-1}
$$

where $c$ is the velocity of light in free space.

In order to have exact results we considered the simulation during 30000 time steps.

The proposed structure has resonant modes at $1550 \mathrm{~nm}$ and $1567 \mathrm{~nm}$ by transmission efficiency of $84 \%$ and $96 \%$, respectively.

When the input wavelength to structure is $1567 \mathrm{~nm}$, it will be dropped from channel-1 and when the input wavelength to structure is $1550 \mathrm{~nm}$, it will be dropped from channel-2, as presented by Fig. 10.

The important parameters to design demultiplexers are central wavelength $\lambda_{0}$, the full width at half power of output $\Delta \lambda$, transmission efficiency and quality factor $Q$. The quality factor is calculated from the following relation

$$
Q=\lambda_{0} / \Delta \lambda \text {. }
$$

The results of this structure are shown in Tab. 1. 


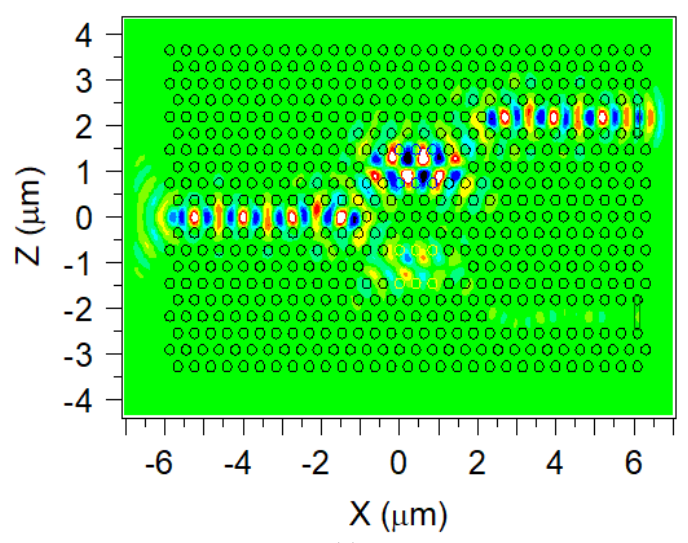

(a)

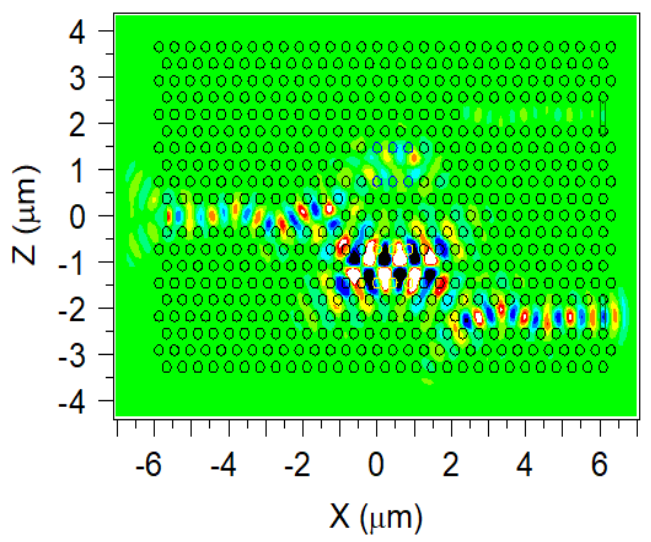

(b)

Fig. 10. Propagation of light in structure (a) with $1567 \mathrm{~nm}$ wavelength input, (b) with $1550 \mathrm{~nm}$ wavelength input.

Another important parameter in wavelength division demultiplexer action is the crosstalk. The resolution of demultiplexer will be increased when the crosstalk decreases. In Tab. 2, the results of the crosstalk between two channels are presented. In the proposed structure, it is shown that the crosstalk between the outputs is acceptable.

Additionally, the comparison of the previous works with the proposed structure is listed in Tab. 3. In all of the previous studies, the method of resizing the radius and movement of the rods or holes has been used to adjust the desired wavelengths but in the present study the telecommunication wavelength separation is performed without any change in size or place of holes.

\begin{tabular}{|l|c|c|c|c|c|}
\hline & $\begin{array}{c}\text { Refractive } \\
\text { index of } \\
\text { optofluidic } \\
\text { liquid }\end{array}$ & $\begin{array}{c}\boldsymbol{\lambda}_{\mathbf{0}} \\
(\mathbf{n m})\end{array}$ & $\begin{array}{c}\Delta \boldsymbol{\lambda} \\
\mathbf{( n m )}\end{array}$ & $\begin{array}{c}\text { Transmission } \\
\mathbf{( \% )}\end{array}$ & $\boldsymbol{Q}$ \\
\hline Channel-1 & 1.47 & 1567.4 & 2.4 & 96 & 653 \\
\hline Channel-2 & 1.31 & 1550.3 & 2.3 & 84 & 674 \\
\hline
\end{tabular}

Tab. 1. Parameters of the proposed structure for different values of refractive index of optofluidic.

\begin{tabular}{|c|c|c|}
\hline Channel & $\mathbf{1}$ & $\mathbf{2}$ \\
\hline $\mathbf{1}$ & $*$ & -18.9 \\
\hline $\mathbf{2}$ & -17.8 & $*$ \\
\hline
\end{tabular}

Tab. 2. Crosstalk value of the proposed structure (dB).

\begin{tabular}{|c|c|c|c|c|c|}
\hline Authors & Channel & $\begin{array}{c}\text { Spectral } \\
\text { width } \\
\text { (average) } \\
\text { (nm) }\end{array}$ & $\begin{array}{c}\text { Channel } \\
\text { spacing } \\
\text { (average) } \\
\text { (nm) }\end{array}$ & $\begin{array}{c}\text { Transmission } \\
\text { efficiency } \\
\text { (average) } \\
\text { (\%) }\end{array}$ & $\begin{array}{c}\text { Quality } \\
\text { factor } \\
\text { (average) }\end{array}$ \\
\hline$[24]$ & 2 & 6.8 & 18 & 86.68 & 75.49 \\
\hline$[25]$ & 4 & $\ldots \ldots$ & 27 & 87 & $\ldots \ldots$ \\
\hline$[26]$ & 2 & $\ldots \ldots$ & 180 & 98.25 & $\ldots \ldots$ \\
\hline$[27]$ & 7 & $\ldots \ldots$ & 31.6 & 40.5 & $\ldots \ldots$ \\
\hline$[28]$ & 3 & 2.73 & 8.2 & 88.3 & 608 \\
\hline$[29]$ & 2 & 4 & 4.4 & 77.5 & 382 \\
\hline$[30]$ & 4 & 2.7 & 6.1 & 94.7 & 556.2 \\
\hline $\begin{array}{c}\text { This } \\
\text { work }\end{array}$ & 2 & 2.35 & 17.1 & 90 & 663.5 \\
\hline
\end{tabular}

Tab. 3. Comparison of the properties of the previous works with the proposed structure.

\section{Conclusion}

In this structure we proposed a two-channel demultiplexer using water and benzene infiltration into specific holes. The filter of channel-1 has resonant mode at $1567 \mathrm{~nm}$ by transmission efficiency of $96 \%$ and the filter of channel-2 has resonant mode at $1550 \mathrm{~nm}$ by transmission efficiency of $84 \%$. The average value of crosstalk and quality factor of our structure are $-18.35 \mathrm{~dB}$ and 663.5 , respectively. In most research activities, the photonic crystal devices have been designed by reducing or increasing the radius of rods or holes at the scales of nanometer and in some cases the fabrication is impossible. However in this study, the results showed that the proposed structure, just by using optofluidic, can be fabricated easily without any change of the holes radius.

\section{References}

[1] DELPHI, G. H., OLYAEE, S., SEIFOURI, M., et al. Design of low crosstalk and high quality factor 2-channel and 4-channel optical demultiplexers based on photonic crystal nano ring resonator. Photonic Network Communications, 2019, vol. 38, no. 2, p. 250-257. DOI: 10.1007/s11107-019-00852-0

[2] VENKATACHALAM, K., SRIRAM KUMAR, D., ROBINSON, $\mathrm{S}$. Investigation on $2 \mathrm{D}$ photonic crystal based eight-channel wavelength-division demultiplexer. Photonic Network Communications, 2017, vol. 34, no. 1, p. 100-110. DOI: 10.1007/s11107-016-0675-7

[3] TAVOUSI, A., MANSOURI-BIRJANDIS, M. A. Study on the similarity of photonic crystal ring resonator cavity modes and whispering gallery-like modes in order of designing more efficient optical power dividers. Photonic Network Communications, 2016, vol. 32 , no. 1, p. 160-170. DOI: 10.1007/s11107-015-0592-1

[4] MEHDIZADEH, F., SOROOSH, M. A new proposal for eightchannel optical demultiplexer based on photonic crystal resonant cavities. Photonic Network Communications, 2015, vol. 31, no. 1, p. 65-70. DOI: $10.1007 / \mathrm{s} 11107-015-0531-1$

[5] ALIPOUR-BANAEI, H., MEHDIZADEH, F., AMINI, B. All optical communication filter based on photonic crystal structure. 
International Journal of Future Computer and Communication, 2015, vol. 4, no. 5, p. 346-349. DOI: 10.18178/ijfcc.2015.4.5.414

[6] SEIFOURI, M., FALLAHI, V., OLYAEE, S. Ultra high-Q optical filter based on photonic crystal ring resonator. Photonic Network Communications, 2018, vol. 35, no. 2, p. 225-230. DOI: 10.1007/s11107-017-0732-x

[7] SVAluto MOREOLO, M., MORRA, V., CINCOTTI, G. Design of photonic crystal delay lines based on enhanced coupled cavity waveguides. Journal of Optics, 2008, vol. 10, no. 6, p. 1-6. DOI: $10.1088 / 1464-4258 / 10 / 6 / 064002$

[8] LIU, T., ZAKHARIAN, A. R., FALLAHI, M., et al. Design of a compact photonic crystal based polarizing beam splitter. IEEE Photonics Technology Letters, 2005, vol. 17, no. 7, p. 1435-1437. DOI: $10.1109 /$ LPT.2005.848278

[9] GHAFFARI, A., MONIFI, F., DJAVID, M., et al. Analysis of photonic crystal power splitters with different configurations. Journal of Applied Sciences, 2008, vol. 8, no. 8, p. 1416-1425. DOI: $10.3923 /$ jas.2008.1416.1425

[10] RAO, W., SONG, Y., LIU, M., et al. All optical switch based on photonic crystal microcavity with multi resonant modes. Optik, 2010, vol. 121, no. 21, p. 1934-1936. DOI: 10.1016/j.ijleo.2009.05.018

[11] THOMSON, D. J., GARDES, F. Y., HU, Y., et al. High contrast $40 \mathrm{Gbit} / \mathrm{s}$ optical modulation in silicon. Optics Express, 2011, vol. 19, no. 12, p. 11507-11516. DOI: 10.1364/oe.19.011507

[12] MOHEBZADEH-BAHABADY, A., OLYAEE, S. All optical NOT and XOR logic gates using a photonic crystal nano-resonator and based on interference effect. IET Optoelectronics, 2018, vol. 12, no. 4, p. 191-195. DOI: 10.1049/iet-opt.2017.0174

[13] MOHEBZADEH-BAHABADY, A., OLYAEE, S. Two curve shaped biosensor for detecting glucose concentration and salinity of seawater based on photonic crystal nano-ring resonator. Sensor Letters, 2015, vol. 13, no. 9, p. 774-777. DOI: $10.1166 /$ s1.2015.3517

[14] REZAEE, S., ZAVVARI, M., ALIPOUR-BANAEI, H. A novel optical filter based on H-shaped photonic crystal ring resonator. Optik, 2015, vol. 126, no. 20, p. 2535-2538. DOI: 10.1016/j.ijleo.2015.06.043

[15] NAGHIZADE, S., SATTARI-ESFAHLAN, S. M. Excellent quality factor ultra-compact optical communication filter on ringshaped cavity. Journal of Optical Communications, 2017, vol. 40, no. 1, p. 1-5. DOI: 10.1515/joc-2017-0035

[16] WANG, Y., CHEN, D., ZHANG, G., et al. A super narrow band filter based on silicon 2D photonic crystal resonator and reflectors. Optics Communications, 2016, vol. 363, p. 13-20. DOI: 10.1016/j.optcom.2015.10.070

[17] ZHUANG, Y., JI, K., ZHOU, W., et al. Design of a DWDM multi/demultiplexer based on 2-D photonic crystals. IEEE Photonic Technology Letters, 2016, vol. 28, no. 15, p. 1669-1672. DOI: 10.1109/LPT.2016.2566662

[18] NAGHIZADE, S., SATTARI-ESFAHLAN, S. M. An optical five channel demultiplexer-based simple photonic crystal ring resonator for WDM applications. Journal of Optical Communications, 2018 , vol. 41, no. 1, p. 1-7. DOI: 10.1515/JOC-2017-0129

[19] BENDJELLOUL, R., BOUCHEMAT, T., BOUCHEMAT, M., et al. New design of T-shaped channel drop filter based on photonic crystal ring resonator. Journal of Nanoscience and Nanotechnology, 2016, vol. 6, no. 1A, p. 13-17. DOI: 10.5923/c.nn.201601.02

[20] VAISI, A., SOROOSH, M., MAHMOUDI, A. Low loss and highquality factor optical filter using photonic crystal-based resonant cavity. Journal of Optical Communications, 2017, vol. 39, no. 3, p. 285-288. DOI: $10.1515 /$ joc-2016-0135
[21] JOHNSON, S. G., JOANNOPOULOS, J. D. Block-iterative frequency domain methods for Maxwell's equations in a plane wave basis. Optics Express, 2001, vol. 8, no. 3, p. 173-190. DOI: 10.1364/OE.8.000173

[22] TAFLOVE, A., HEGNESS, S. C. Computational Electrodynamics: The Finite Difference Time Domain Method. $3^{\text {rd }}$ ed., rev. London (UK): Artech House, 2005. ISBN: 9781580538329

[23] SAUNDERS, J. E., SANDERS, C., CHEN, H., et al. Refractive indices of common solvents and solutions at $1550 \mathrm{~nm}$. Applied Optics, 2016, vol. 55, no. 4, p. 947-953. DOI: 10.1364/AO.55.000947

[24] TEKESTE, M. Y., YARRISON-RICE, J. M. High efficiency photonic crystal based wavelength demultiplexer. Optics Express, 2006, vol. 14, no. 17, p. 7931-7942. DOI: 10.1364/OE.14.007931

[25] DJAVID, M., MONIFI, F., GHAFFARI, A., et al. Heterostructure wavelength division demultiplexers using photonic crystal ring resonators. Optics Communications, 2008, vol. 281, no. 15-16, p. 4028-4032. DOI: 10.1016/j.optcom.2008.04.045

[26] ZHANG, X., LIAO, Q., YU, T., et al. Novel ultracompact wavelength division demultiplexer based on photonic band gap. Optics Communications, 2011, vol. 285, no. 3, p. 274-276. DOI: 10.1016/J.OPTCOM.2011.10.001

[27] BOUAMAMI, S., NAOUM, R. Compact WDM demultiplexer for seven channels in photonic crystal. Optik, 2012, vol. 124, no. 16, p. 2373-2375. DOI: 10.1016/j.ijleo.2012.08.008

[28] MANSOURI-BIRJANDI, M. A., RAKHSHANI, M. R. A new design of tunable four port wavelength demultiplexer by photonic crystal ring resonators. Optik, 2013, vol. 124, no. 23, p. 5923-5926. DOI: 10.1016/j.ijleo.2013.04.128

[29] ALIPOUR-BANAEI, H., SERAJMOHAMMADI, S., MEHDIZADEH, F. Effect of scattering rods in the frequency response of photonic crystal demultiplexers. Journal of Optoelectronics and Advanced Materials, 2015, vol. 17, n. 3-4, p. 259-263. ISSN: 1454-4164

[30] RAKHSHANI, M. R., MANSOURI-BIRJANDI, M. A. Design and simulation of wavelength demultiplexer based on heterostructure photonic crystals ring resonators. Physica E, 2013, vol. 50, p. 97-101. DOI: 10.1016/jphyse.2013.03.003

\section{About the Authors ...}

Mahsa BAZARGANI received the B.Sc. degree in Electrical Engineering from Islamic Azad University, Yazd Branch, Iran, in 2007 and M.Sc. degree in Telecommunication Engineering from Islamic Azad University, Bushehr Branch, Iran, in 2012. She is currently working toward the Ph.D. degree in Islamic Azad University, Central Tehran Branch, Iran. Her research activity has been focused in the optic and photonic structures used in telecommunication.

Behnaz GHAREKHANLOU received her B.Sc. in Electrical Engineering from Iran University of Science and Technology, Tehran, Iran, in 2005 and the M.Sc. and Ph.D. degrees in Electrical Engineering from Sharif University of Technology, Tehran, in 2008 and 2014, respectively. She is currently an Assistant Professor of Electrical Engineering with the School of Electrical Engineering at Islamic Azad University, Central Tehran Branch. Her active research areas include optics, photonics, and solid-state electronics. 
Mehdi BANIHASHEMI received his M.Sc. from Urmia University in 2002, and Ph.D. from Tarbiat Modares University in 2013, all in Electronics Engineering. He is an Assistant Professor at Islamic Azad University Central
Tehran Branch. His current research interests include perovskite and organic solar cells, photonic crystals, quantum dot lasers, optoelectronic devices, and analog microelectronic circuit design. 